AUTORES:

António Rebelo ${ }^{1}$

João Brito ${ }^{1}$

Luís Fernandes ${ }^{1}$

Pedro Silva ${ }^{1}$

Paul Butler ${ }^{2}$

Alberto Mendez-Villanueva ${ }^{3}$

André Seabra ${ }^{1}$

${ }^{1} \mathrm{CIFI}^{2} \mathrm{D}$, Faculdade de Desporto, Universidade do Porto, Portugal

${ }^{2}$ Department of Exercise and Sport Sciences, Manchester Metropolitan University, Alsager, United Kingdom

${ }^{3}$ Physiology Unit, Performance Enhancement and Talent Identification Section, ASPIRE, Academy for Sports Excellence, Doha, Qatar
Physiological, technical and time-motion responses to goal scoring versus ball possession in Soccer small-sided games.

\section{PALAVRAS CHAVE:}

Association football. Time-motion. Heart-rate.

Technical actions. Pitch dimension.

\title{
ABSTRACT
}

This study aimed to compare the activity profile, exercise intensity and technical actions of goal-scoring (GS) and ball-possession (BP) small-sided games (SSGs). Ten youth male amateur soccer players (mean SD: age 17.20 .6 yrs; height $175.25 .4 \mathrm{~cm}$; weight 70.99 .3 $\mathrm{kg}$ ) completed two different SSGs: $5 \mathrm{v} 5$ ball-possession game without goalkeeper (GK), and $5 v 5$ goal-scoring game with GK. Both SSGs were played in three different field dimensions (length $\times$ width): $30 \times 20$ m, $40 \times 30$ m, $50 \times 40$ m, in which heart rate (HR), time-motion characteristics and technical skills performance were recorded. Each SSG lasted 10 minutes interspaced by 10-minute active recovery intervals. The mean duration of jogging and striding actions was higher in BP than in GS. BP involved more time spent in jogging and striding and more time spent above $90 \%$ maximal $H R\left(\mathrm{HR}_{\max }\right)$. During $\mathrm{GS}$ the percentage of time $<80 \% \mathrm{HR}_{\max }$ was significantly higher when compared with BP. A higher number of passes and touches on the ball were also observed in BP. In conclusion, the present study showed that the BP induced an increase in exercise intensity and technical actions. Therefore, in young amateur soccer players, BP SSGs may be preferable to GS SSGs when the concurrent development of technical factors and soccer-specific fitness are key objectives. 


\section{Respostas fisiológicas, técnicas e físicas \\ em jogos reduzidos de futebol \\ com balizas versus jogos de manutenção}

da posse da bola.

\section{RESUMO}

O presente estudo teve como objectivo comparar o perfil de atividade, a intensidade de exercício e as ações técnicas de dois tipos de jogos reduzidos (JR) de futebol: jogos de manutenção da posse da bola (PB) e jogos com balizas (B). Dez jogadores de futebol amadores (média \pm DP: idade $17.2 \pm 0.6$ anos; altura $175.2 \pm 5.4 \mathrm{~cm}$; peso $70.9 \pm 9.3 \mathrm{~kg}$ ) realizaram dois tipos de JR: $5 \mathrm{v} 5$ com manutenção da posse da bola sem guarda-redes (GR) e $5 \times 5$ com balizas e GR. Ambos os exercícios foram realizados em diferentes áreas de jogo (comprimento x largura): 30x20 m, $40 \times 30 \mathrm{~m}, 50 \times 40 \mathrm{~m}$. Foram analisados a frequência cardíaca (FC), o perfil de atividade e as ações técnicas. Cada JR foi realizado durante $10 \mathrm{~min}$ após os quais se seguiram $10 \mathrm{~min}$ de repouso. As durações média e total dos deslocamentos em corrida lenta e em corrida de média intensidade foram maiores nos $\mathrm{PB}$ do que nos $\mathrm{B}$. Os PB envolveram também mais tempo com valores de $\mathrm{FC}$ acima de $90 \%$ da $\mathrm{FC}$ máxima $\left(\mathrm{FC}_{\max }\right)$. Durante os $\mathrm{B}$ a percentagem de tempo com valores de $\mathrm{FC}<80 \% \mathrm{FC}_{\max }$ foi mais alta do que nos PB. Os PB mostraram também um numero superior de passes e de toques na bola. Em conclusão, o presente estudo mostrou que os JR de PB apresentaram uma maior intensidade de exercício e de ações técnicas. Desta forma, no treino de jovens jogadores de futebol, os JR de PB devem ser adoptados quando se pretende o desenvolvimento concorrente de factores técnicos e da condição física específica.

\section{PALAVRAS CHAVE:}

Futebol. Análise de tempo-movimento. Frequência cardíaca.

Ações técnicas. Área do campo. 
The use of drills performed on a smaller size pitch and a reduced number of players, commonly known as small-sided games (SSGs), has been widely adopted by many coaches in both amateur and professional soccer ${ }^{(5)}$. The potential for these SSGs to replicate competitive situations and to concurrently train soccer-specific physical and technical skills justifies their common utilisation ${ }^{(5,6,7)}$.

Different physiological, technical and time-motion responses during SSGs can be obtained with the manipulation of certain variables such as pitch dimensions, number of players, coach encouragement and rules $(1,4,7)$. However, very little is known on the effects of varying the tactical goal of the SSG on its physical, physiological and technical components ${ }^{(4)}$. This is unfortunate because coaches use different SSGs to train tactical aspects. Knowledge on the effects of varying the tactical goal on exercise intensity and technical scores would assist coaches and fitness coaches in integrating SSGs into the soccer training process. Goal-scoring (GS) SSGs, which main aim is to score goals and prevent the opposition to do it and ball-possession (BP) SSGs, which main aim is to keep the ball possession as long as possible, are two of the most popular tactical SSGs employed by soccer coaches ${ }^{(5,7)}$. However, to the best our knowledge, no previous study has described the responses of these two different SSGs formats Therefore, the aim of this study was to compare the physiological, technical and time-motion responses associated with two SSGs (GS vs. BP) in young soccer players. A secondary aim was to examine the influence of the size of the pitch in the SSGs.

\section{METHODS}

\section{EXPERIMENTAL APPROACH TO THE PROBLEM}

In this study, we aimed to examine the effect of the tactical goal (independent variable) on exercise intensity, technical scores and time motion responses (dependent variables) during SSGs. Two different tactical rules (i.e., GS and BP) that are commonly used by soccer coaches were applied to $5 \mathrm{vs5}$ SSGs. Both SSGs were performed in three different field dimensions (length $x$ width): 30×20 m (small, S), 40×30 m (medium, M), 50×40 m (large, L).

\section{SUBJECTS}

Ten young male amateur soccer players (mean \pm SD; age, $17.2 \pm 0.6 \mathrm{yr}$; height, $175.2 \pm 5.4$ $\mathrm{cm}$; weight, $70.9 \pm 9.3 \mathrm{~kg}$; maximal heart rate $\left.\left(\mathrm{HR}_{\max }\right), 193.4 \pm 8.1 \mathrm{bpm}\right)$ participated in this study. The study was conducted after a 6-week preseason period. The weekly training schedule included at least 3 training sessions of $90 \mathrm{~min}$ and a match. The SSGs evaluated were common exercises of the team training routines. The coach divided the players in two 
homogeneous teams based on his awareness and experience with the individual player performance. Written informed consent was obtained from both the players and their parents. The local University Ethical Committee approved the experimental protocol.

\section{PROCEDURES}

In two training sessions (separated at least by 7 days), two different SSGs were performed: 5v5 GP and 5v5 BP. Both SSGs were performed in three different field dimensions: $S, M$ and L. Each SSG lasted 10 minutes interspaced by 10-minute active recovery intervals. Verbal encouragement from the coaches was given.

Players' movements during the SSGs were obtained from video recordings according to the procedures described by Gabbett and Mulvey ${ }^{(2)}$. A validated game-oriented authentic assessment procedure ${ }^{(3)}$ was used to evaluate technical parameters (i.e., passing actions, balls receptions and lost balls). Heart rate (HR) was recorded at 5 second intervals during each SSG via short-range radio telemetry (Polar Team System, Polar Electro, Finland). The individual maximal $\mathrm{HR}\left(\mathrm{HR}_{\max }\right)$ was previously determined by the individuals' highest value reached during the Yo-Yo Intermittent Recovery Test - level 1.

\section{STATISTICAL ANALYSIS}

Descriptive statistics are reported as means \pm standard deviations. Differences between SSGs were tested with a two way ANOVA for repeated measures. When significant interaction effects were found, Bonferroni's post-hoc comparisons were applied. Statistical significance was set at 0.05 .

\section{RESULTS}

Figure 1 shows the HR responses associated with the various SSG formats. There were no differences in mean HR values between $\mathrm{GS}$ and $\mathrm{BP}(\mathrm{S}, 174 \pm 8 \mathrm{bpm} ; \mathrm{M}, 174 \pm 9 \mathrm{bpm}$; $\mathrm{L}$, $175 \pm 7 \mathrm{bpm}$ vs. S, $159 \pm 14 \mathrm{bpm} ; \mathrm{M}, 161 \pm 8 \mathrm{bpm}$; L, $159 \pm 10 \mathrm{bpm})$. The percentage of time spent in the intensity zone $>90 \% \mathrm{HR}_{\max }$ was higher in BP than in GS, with the only exception of $S$ pitch size. On the contrary, GS induced significantly higher values than BP in the time spent in exercise intensities below $80 \% \mathrm{HR}_{\max }$ in all pitch sizes tested. 


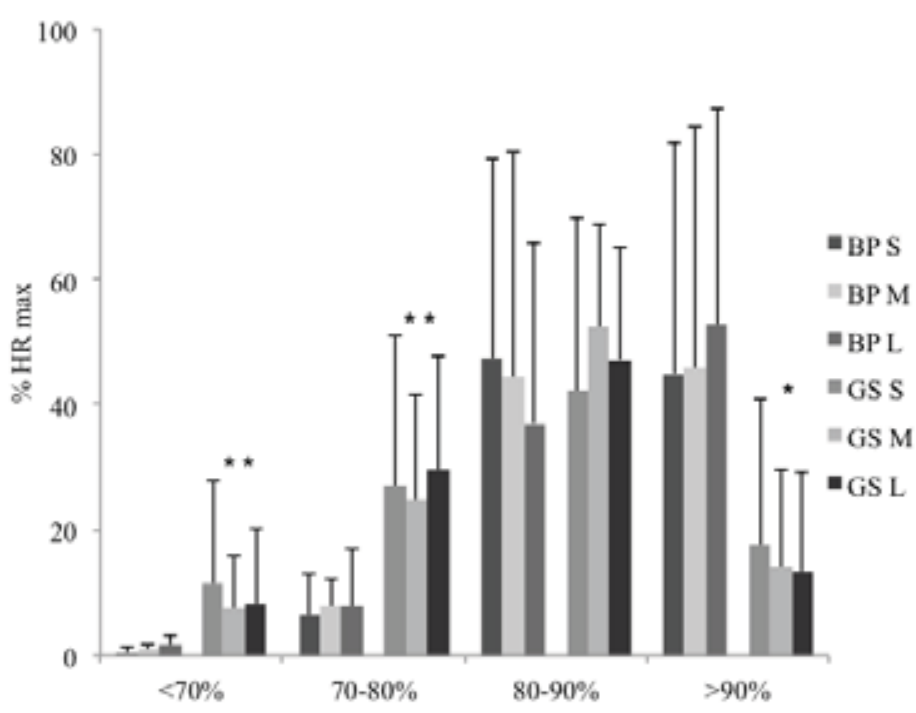

LEGEND: S, small size ( $30 \times 20 \mathrm{~m})$ pitch; M, medium size $(40 \times 30 \mathrm{~m})$ pitch; L, large size $(50 \times 40$ m) pitch. ${ }^{*} B P-S S G>$ GS-SSG in M and L, $p<0.05$; **BP-SSG different from GS-SSG in all pitch dimensions, $p<0.05$.

FIGURE 1 - Percentage of playing time spent on each heart rate zone during two small-sided games (SSG) formats (BP, ball possession and GS, goal scoring).

Higher technical scores were observed in BP than in GS, especially in the smallest pitch size tested. In BP, players completed a higher number of passes across all pitch dimensions ( $\mathrm{S}$, $18 \pm 4$ vs. $11 \pm 5 ; M, 15 \pm 4$ vs. $9 \pm 3 ; L, 14 \pm 6$ vs. $11 \pm 7 ; p<0.05)$ and also a higher number of touches on the ball in $S(20 \pm 5$ vs. $15 \pm 5 ; p=0.004)$. However, the number of skills errors was lower in GS than in BP in $S$ and $M$ pitches ( $5 \pm 2$ vs. $10 \pm 4$ and $4 \pm 2$ vs. $7 \pm 3$, respectively).

Players spent more time standing and walking in GS than in BP (Figure 2). BP played in $S$ and $M$ pitches resulted in more time jogging and striding than in $G S(p<0.05)$. Time spend striding was also higher in BP than in $G S(p<0.05)$. There were no differences for the time spent sprinting. 


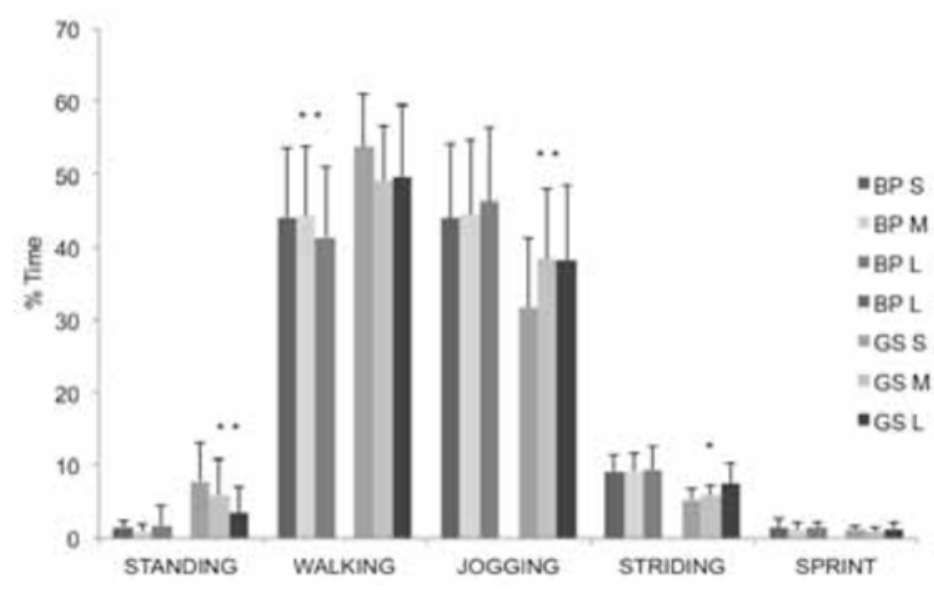

Legend: S, small size $(30 \times 20 \mathrm{~m})$ pitch; $M$, medium size $(40 \times 30 \mathrm{~m})$ pitch; L, large size $(50 \times 40 \mathrm{~m})$ pitch. ${ }^{*}$ BP-SSG > GS-SSG G in S and M, p<0.01; **BP-SSG different from GS-SSG in all pitch dimensions, $p<0.05$.

FIGURE 2 - Percentage of playing time spent on each locomotor category during two small-sided games (SSG) formats (BP, ball possession and GS, goal scoring).

\section{DISCUSSION}

The main finding of the present study was that games with a tactical emphasis on ball possession resulted in an increased exercise intensity, technical load and physical effort in comparison with games emphasizing ball position.

The most likely explanation for the overall higher running demands and exercise intensity during BP SSGs (as evidenced by HR responses) compared with GS SSGs could be related to the fact that in BP players constantly need to create passing lines, or block the opponents passing lines, probably leading to a greater number of movements. On the contrary, the lower running intensity associated with the GS could be linked to the primary objective of the game, that is scoring goals. In this regard, the presence of goals might have led the players to behave in a manner closer to that of the formal 11-a-side game, which would result in a more rational distribution of the payers on the field. Furthermore, the inclusion of GKs would result in the increase of time that the ball is stopped in their hands or feet, which could slow down the match-playing tempo and consequently exercise intensity.

In addition to the higher overall exercise intensity, BP imposed higher technical demands (more involvement with the ball and number of passes) than GS. Previous research has shown that these two specific technical skills (involvements with the ball and short passes) differentiated players from the more successful and from the less successful 
professional teams ${ }^{(8)}$. Thus, present results suggest that BP can be used to train these important technical traits in situations of physiological overload during soccer practise. However, it must be noted that, contrary to GS, other relevant soccer-specific skills, such as shooting, are not performed in BP.

To summarise, the present study using $5 \mathrm{v} 5$ formats showed that BP resulted in increased overall exercise intensity and technical involvements than GS. These results provide additional information on the factors affecting exercise intensity in SSGs. This information may be useful for prescribing soccer-specific conditioning sessions in young soccer players.

\section{PRATICAL APPLICATIONS}

Ball possession-based small-sided games resulted in more skill involvements and a higher overall training intensity than goal scoring small-sided games. Thus, when designing training sessions, practitioners should be aware that ball-possession small-sided games are preferred than goal-scoring to concurrently target important technical skills (passes and ball reception) and soccer-specific physical fitness. 


\section{REFERENCES}

1. Bangsbo J, Lindquist F (1992). Comparison of various exercise tests with endurance performance during soccer in professional players. Int J Sports Med, 13: 125-132.

2. Gabbett T, Mulvey M (2008). Time-motion analysis of small-sided training games and competition in elite women soccer players. J Strength Cond Res, 22: 543-552.

3. Gréhaigne J, Godbout P, Bouthier D (1997). Performance Assessment in Team Sports. J Teaching Phys Edu, 16: 500-516.

4. Hill-Haas S, Dawson B, Coutts A, Rowsell G (2009). Physiological responses and time-motion characteristics of various small-sided soccer games in youth players. J Sports Sci, 27: 1-8.

5. Little T, Williams A (2006). Suitability of soccer training drills for endurance training. J Strength Cond Res, 20: 316-319.

6. Mallo J, Navarro E (2008). Physical load imposed on soccer players during small-sided training games. J Sports Med Phys Fitness, 48: 166-172.

7. Rampinini E, Impellizzeri F, Castagna C, Abt G, Chamari K, Sassi A, Marcora S (2007). Factors influencing physiological response to small-sided soccer games. J Sports Sci, 25: 659-666.

8. Rampinini E, Impellizzeri F, Castagna C, Coutts A, Wisløff U (2009). Tecnhical performance during soccer matches of the Italian serie A league: Effect of fatigue and competitive level. J Sci Med Sport, 12: 227-233. 